OPEN ACCESS

Edited by:

Angelo Sala,

University of Milan, Italy

Reviewed by:

Patrizia Risé,

University of Milan, Italy

Pallavi R. Devchand,

University of Calgary, Canada

*Correspondence:

Sebastiano Banni

banni@unica.it

${ }^{\dagger}$ These authors contributed equally to this work

Specialty section: This article was submitted to Inflammation Pharmacology,

a section of the journal

Frontiers in Pharmacology

Received: 24 July 2020 Accepted: 17 November 2020

Published: 08 January 2021

Citation:

Murru E, Carta G, Manca C, Sogos V, Pistis M, Melis M and Banni S (2021)

Conjugated Linoleic Acid and Brain Metabolism: A Possible AntiNeuroinflammatory Role Mediated by PPARa Activation.

Front. Pharmacol. 11:587140 doi: $10.3389 /$ fphar.2020.587140

\section{Conjugated Linoleic Acid and Brain Metabolism: A Possible Anti-Neuroinflammatory Role Mediated by PPARa Activation}

\author{
Elisabetta Murru ${ }^{1 \dagger}$, Gianfranca Carta ${ }^{1 \dagger}$, Claudia Manca ${ }^{1}$, Valeria Sogos ${ }^{1}$, Marco Pistis ${ }^{1,2}$, \\ Miriam Melis ${ }^{1}$ and Sebastiano Banni ${ }^{1 *}$
}

${ }^{1}$ Department of Biomedical Sciences, University of Cagliari, Monserrato, Italy, ${ }^{2}$ Neuroscience Institute, National Research Council of Italy (CNR), Cagliari, Italy

Fatty acids play a crucial role in the brain as specific receptor ligands and as precursors of bioactive metabolites. Conjugated linoleic acid (CLA), a group of positional and geometric isomers of linoleic acid ( $L A, 18: 2 n-6)$ present in meat and dairy products of ruminants and synthesized endogenously in non-ruminants and humans, has been shown to possess different nutritional properties associated with health benefits. Its ability to bind to peroxisome proliferator-activated receptor (PPAR) a, a nuclear receptor key regulator of fatty acid metabolism and inflammatory responses, partly mediates these beneficial effects. CLA is incorporated and metabolized into brain tissue where induces the biosynthesis of endogenous PPARa ligands palmitoylethanolamide (PEA) and oleoylethanolamide (OEA), likely through a positive feedback mechanism where PPARa activation sustains its own cellular effects through ligand biosynthesis. In addition to PPARa, PEA and OEA may as well bind to other receptors such as TRPV1, further extending CLA own anti-neuroinflammatory actions. Future studies are needed to investigate whether dietary CLA may exert antiinflammatory activity, particularly in the setting of neurodegenerative diseases and neuropsychiatric disorders with a neuroinflammatory basis.

Keywords: conjugated linoleic acid, peroxisome proliferator-activated receptor $\boldsymbol{\alpha}$, brain, neuroinflammation, lipid nutrition

\section{INTRODUCTION}

Fatty acids (FAs) are ubiquitous biological molecules that are used as metabolic fuels, essential components of cellular membranes and regulators of signaling molecules. Any tissue has its own peculiar preferential use for FAs: some are more prone for $\beta$-oxidation (e.g., muscles), others for the formation and the processing of bioactive metabolites (e.g., brain), or FA accumulation in the form of triglycerides (e.g., adipose tissue), or for the regulation and formation of desaturated/elongated metabolites (e.g., liver) and their release into the bloodstream for their transport to different tissues. In order to properly carry out all of these metabolic pathways, some sort of intracellular "sensor" is required, which can selectively drive FA metabolism according to cell tissue requirements and upon FA tissue availability. To this aim, the "elaboration" or the processing of dietary FAs are important to fulfill tissue FA requirements. Additionally, even though within a definite range, dietary FAs affect tissue composition, thereby directly or indirectly (i.e., through their metabolites) regulating FAderived signaling molecules. 
Conjugated linoleic acid (CLA), is a group of positional and geometric isomers of linoleic acid (LA, 18:2 n-6) present in meat and dairy products of ruminants (Martins et al., 2007), and endogenously synthesized in non-ruminants and in humans (Shingfield and Wallace, 2014). The most studied isomers are $c 9, t 11$, the natural isomer mostly present in foods, and $t 10, c 12$ mainly present in nutraceutical supplements.

As a consequence, plasma basal level of c,9t11 CLA has been detected (around $15 \mathrm{nmoles} / \mathrm{ml}$ ), as well as its metabolites. Interestingly, following supplementation, the plasma concentrations of c9,t11CLA and its metabolites were incorporated in a linear fashion (Mele et al., 2013).

Biological properties exerted by these isomers can be different or shared, depending on the effect and the tissue (Churruca et al., 2009) and have been shown to possess different nutritional properties (Belury, 2002; den Hartigh, 2019). However, some adverse effects have been described for the isomer c9,t11-CLA, such as increased levels of C-reactive protein (Smedman et al., 2005), a small decrease of insulin sensitivity of about $14.4 \pm$ $16.7 \%$, and increased levels of isoprostane, a marker of lipid peroxidation of $50 \pm 40 \%$ in obese man (Riserus et al., 2004). t10,c12 CLA has also been shown to induce a small increase of isoprostane, compared with the isomer c9,t11 CLA (Tholstrup et al., 2008). However, the same group demonstrated that the isoprostane increase was not associated with risk markers of cardiovascular disease, inflammation, or fasting concentrations of insulin and glucose (Raff et al., 2008). Notably, isoprostane increase is suggested to not be ascribed to an ongoing lipid peroxidation, but rather to its reduced catabolism in peroxisomes due to a competition with CLA (Iannone et al., 2009). In order to evaluate potential adverse effects of CLA in humans, Wanders et al. designed a study on 61 healthy volunteers, which were administered with $20 \mathrm{~g} /$ days of a c9,t11 and t10,c12 CLA isomers 80/20 mixture (Wanders et al., 2010a), and showed no changes in either lipoprotein profile or in liver and kidney function (Wanders et al., 2010b).

The numerous and contrasting biological effects reported for CLA (Benjamin et al., 2015) are probably due to its pleiotropic properties, and may not be explained by a single biochemical mechanism (Kennedy et al., 2008), although they are generally ascribed to its activities on lipid and energy metabolism. CLA metabolism, extensively studied especially in rodents (Banni et al., 1995; Belury and KempaSteczko, 1997; Sebedio et al., 1997), probably influences the metabolism of n-6 polyunsaturated FAs (PUFA) by competing for their formation (Banni et al., 1999; Banni, 2002) and enhances the formation of docosahexaenoic acid (DHA, 22:6 n-3) in experimental animals (Piras et al., 2015; Carta et al., 2019) and humans (Murru et al., 2018), by inducing peroxisomal $\beta$-oxidation (Ferdinandusse et al., 2003).

In a study performed on neonatal piglets fed with or without supplementation of CLA for $16^{\circ}$ days, aimed at investigating the incorporation and metabolism of CLA isomers in brain tissue (Lin et al., 2011), the authors showed that CLA significantly affected the biosynthesis of long-chain PUFA in liver and brain tissues by inhibiting LA elongation/desaturation pathways. The inhibitory effects were dependent on the reduced activity of delta
6 desaturase/elongase-5 ( $\Delta 6 \mathrm{D} /$ Elovl-5) and especially the alternate Elovl-A elongation/desaturation pathway and were associated with the fat content and the corresponding PUFA levels in the dietary fat (Lin et al., 2011).

In addition, it has been recently shown that dietary intake of CLA induced the biosynthesis of oleoylethanolamide (OEA) and palmitoylethanolamide (PEA) in the liver of obese Zucker rats, an effect associated to a reduced hepatic lipid deposition (Piras et al., 2015). OEA and PEA are natural ethanolamides of oleic acid (OA, 18:1 n-9) and palmitic acid (PA, 16:0), respectively. OEA reduces food intake and body weight gain in obese rats (Fu et al., 2005), stimulates lipolysis and FA oxidation (Guzman et al., 2004), reduces the content of triacylglycerol (TAG) in both the liver and adipose tissue (Guzman et al., 2004). All of these properties may be attributed to CLA ability to activate specific receptors such as peroxisome proliferator-activated receptors (PPAR) $\alpha, \beta / \delta$ and AMP-activated protein kinase (AMPK) (Trinchese et al., 2020). Despite the high brain expression of PPAR $\beta$ and its possible role in regulating the metabolism of FAs and/or cholesterol, in inflammation processes and antioxidant mechanisms brain (Hall et al., 2008), very little is known nowadays about how CLA regulates this nuclear receptor in the healthy and diseased brain.

PPAR $a$ is a ubiquitous ligand-activated transcriptional factor that belongs to the family of nuclear receptors. PPAR $\alpha$ regulates the expression of genes involved in FA metabolism, $\beta$-oxidation in both mitochondria and peroxisomes, acting as an intracellular FA sensor and regulating FA trafficking according to cell tissue requirements upon tissue FA availability. The discovery that FA are endogenous ligands of PPARa occurred when Gottlicher et al. (Gottlicher et al., 1992) tested the capability of FA to activate PPARa upon the observation that the class of synthetic PPARa agonists fibrates and FA displayed similar biological activity. Indeed, fibrates and FA induce a conformational change of the PPARs, triggering the transcription of genes encoding for metabolic and cellular processes such as FA $\beta$-oxidation and adipogenesis representing key mediators of lipid homeostasis (Echeverria et al., 2016). Along with other studies, a bewildering array of compounds activating PPAR $a$ has been discovered (Schoonjans et al., 1996). However, all the efforts made to demonstrate that these compounds directly bind to PPARa have failed. This has led to the hypothesis that these compounds alter FA metabolism, which indirectly leads to the accumulation of endogenous PPARa ligands (Gottlicher et al., 1993). A ligand-binding assay has been developed that facilitates the identification of ligands for PPAR $a$ and PPAR $\beta / \delta$. It has been found that fibrates and specific FA/ eicosanoids can bind to these receptors. This indicates that FA simultaneously serve as intermediary metabolites and as primary regulators of transcriptional networks (Forman et al., 1997).

Even though the comparison of the ligand activity among different fatty acids is extremely difficult to assess because their cellular concentration may vary greatly in different tissues, Krey et al. (1997) using co-activator-dependent receptor ligand assay (CARLA), screened several FA and found LA and linolenic acids the most affine to PPARa. Interestingly, Moya-Camarena et al. found that CLA was by far more potent inducer than LA (MoyaCamarena et al., 1999). 
PPARa is also a key regulator of inflammatory responses (Delerive et al., 2001; Korbecki et al., 2019): its antiinflammatory effects are primarily mediated through their abilities (shared with the other PPARs) to trans-repress (Ricote and Glass, 2007) the functions of many activated transcription factors, such as the transcription factor nuclear factor- $\mathrm{kB}(\mathrm{NF}-\mathrm{kB})$, signal transducers and activators of transcription (STATs), activator protein 1 (AP1) and nuclear factor of activated T cells (NFAT) (Daynes and Jones, 2002; Wahli and Michalik, 2012). Data suggested that these metabolic and anti-inflammatory effects are not restricted to the periphery but also occur in the CNS. Therefore, if CLA is an avid ligand of PPARa, it may as well possess anti-neuroinflammatory properties. If so, it must be first incorporated into cell tissue lipids in order to bind to PPARa.

\section{Conjugated Linoleic Acid Incorporation and Metabolism in Brain Tissue in Rats and Humans}

In peripheral tissues, CLA incorporation is prompt and its deposition occurs particularly in neutral lipids (NL). CLA and its desaturated and elongated metabolites are likely biosynthesized and then transported to extrahepatic tissues, as evidenced by their high concentration also in plasma and adipose tissue after dietary CLA administration. Given that modification of FA profile in the brain by dietary FAs is quite difficult (Zamberletti et al., 2017; Carta et al., 2019; Carta et al., 2020), this is also true for dietary CLA.

In rats fed a diet supplemented with $150 \mathrm{mg} /$ day of $9 \mathrm{c}, 11 \mathrm{t}$ or $9 t, 11 \mathrm{t}$ or $10 \mathrm{t}, 12 \mathrm{c}$ or $10 \mathrm{t}, 12 \mathrm{t}$ isomers for six days, only minor changes in CLA brain concentrations were found (Alasnier et al., 2002). This might be due to either 1) a preferential incorporation of CLA in tissue TAG (Banni et al., 2001; Paterson et al., 2002) and the relative virtual lack of this lipid fraction in brain tissue; or 2) a very selective and steady incorporation of FAs in the brain (Salem and Niebylski, 1995); or else 3) a rapid CLA metabolism to other conjugated FAs in the brain.

$\mathrm{Fa}$ and co-workers (Fa et al., 2005) administered a single dose of CLA ( $2 \mathrm{~g}$ by gavage) to female Sprague-Dawley rats to monitor its incorporation and metabolization up to $24 \mathrm{~h}$. Confirming previous research, CLA incorporation was much lower in the brain than in the other tissues examined. At $24 \mathrm{~h}$ CLA isomer concentrations were both increased by four folds in plasma and liver and two folds in brain, whereas in adipose tissue 9c,11t isomer increased six folds and t10,c12 by four folds. However, a relative high accumulation of CLA metabolites was found, particularly products of peroxisomal $\beta$-oxidation related to the content of the precursor. The discrete levels of the two CLA isomers measured in plasma could be ascribed to the different rates of hydrolyzation of the isomers in chylomicron TAG by lipoprotein lipase. In the brain, the level of the t10,c12 isomer was lower than that of the $c 9, \mathrm{t} 11$ isomer, probably because of the enhanced metabolism of $\mathrm{t} 10, \mathrm{c} 12$ with respect to $\mathrm{c} 9, \mathrm{t} 11$, as shown by higher concentrations of $\mathrm{t} 10, \mathrm{c} 12$ metabolites. $\mathrm{t} 10, \mathrm{c} 12$ seemed to be $\beta$-oxidized very efficiently in all tissues, particularly in the brain. Products of peroxisomal $\beta$-oxidation of CLA were detected in experiments in vivo and in vitro, confirming that CLA could act as a ligand to brain PPARa (Cullingford et al., 1998; Moreno et al., 2004).

Interestingly, astrocytes may play a crucial role on CLA metabolization as confirmed by in vitro studies ( $\mathrm{Fa}$ et al., 2005). Cerebellar astrocytes were isolated from 7 days-old Sprague-Dawley rats and treated with $100 \mu \mathrm{M}$ of CLA mixture, were shown to produce relevant concentration of CLA metabolites. These results suggest that activation of PPAR-mediated differentiation pathways could be a mechanism by which CLA could exert beneficial effects on the brain, especially in disorders characterized by an impairment of peroxisomal $\beta$-oxidation inducing demyelination of nerve fibers. This is the case of $\mathrm{X}$-linked adrenoleukodystrophy (ALD), characterized by an abnormal accumulation of very long-chain FAs (VLCFA), owing to defects of the ALDP, an integral peroxisomal membrane protein (Douar et al., 1994), specifically 26:0 which is almost exclusively $\beta$-oxidized in peroxisomes. The increase of VLCFA intercalated in the membrane may account for demyelination and increased immunoreactivity (Baes and Aubourg, 2009). A mixture of glycerol trioleate and glycerol trierucate, 4:1, Lorenzo's oil (LO), reduced plasma levels of VLCFA competitively inhibiting the elongase that forms VLCFA. However, LO decreased plasma VLCFAs, while it did not prevent ALD (Di Biase and Markus, 1998), probably because erucic acid (22:1) may not accumulate sufficiently into brain lipids due to very low desorption (Poulos et al., 1994; Hamilton et al., 2007). Cappa and co-workers (Cappa et al., 2012) treated five ALD women, who were not treated with LO therapy at the study entry, with a mixture of LO ( $40 \mathrm{~g} /$ day $)$ plus a mixture of CLA ( $5 \mathrm{~g} /$ day) for 2 months, a dose sufficiently high to be incorporated in the central nervous system (CNS). Treatment with the mixture LO + CLA significantly increased CLA levels to $50 \mathrm{nmol}$ and $1,2 \mathrm{nmol} / \mathrm{ml}$ (around five and two folds vs. the baseline levels) in plasma and CSF respectively. This approach was based on the hypothesis that CLA may act synergistically with LO, as CLA is a high-affinity ligand of PPARa (Moya-Camarena et al., 1999), and might thereby induce the key enzymes for peroxisomal $\beta$-oxidation (Reddy and Hashimoto, 2001).

CLA may also contribute to the shortening of 24:0 and ameliorate eicosanoid and oxidative stress product catabolism by increasing peroxisomal $\beta$-oxidation, acting as an antiinflammatory and antioxidative factor. In all patients, the $\mathrm{LO}+$ CLA mixture treatment decreased plasma levels of VLCFA, while increased CLA levels in plasma and cerebrospinal fluid (CSF) and the docosahexaenoic acid/eicosapentaenoic acid (22:6/ 20:5) ratio, an indirect marker of peroxisomal $\beta$-oxidation induced by PPARa (Ferdinandusse et al., 2002). Cappa et al. study demonstrated for the first time that CLA promptly crosses the human blood-brain barrier (Cappa et al., 2012). Furthermore, because there was a correlation between changes of CLA concentrations in CSF and plasma, this may suggest that the linear dose-response found in plasma of experimental animals (Banni et al., 1999) and more recently in humans (Murru et al., 2018) may also occur in CSF. 


\section{In Vivo Brain CLA Effects in Experimental Animals and Humans}

Although CLA isomers are incorporated and metabolized in the brain of several species, pieces of evidence about its impact on brain function are still limited, not being adequately addressed in both experimental animals and humans.

Different studies evaluated the potential benefits of CLA on neurodegenerative diseases as Alzheimer's disease (AD) or other disorders that may contribute to dementia in elderly people by modulating the neuroinflammation in the brain. The brain seems to be exceptionally susceptible to peroxidation, and neurodegenerative diseases are accompanied by the activation of defensive mechanisms such as astrogliosis (Rojo et al., 2014), macroautophagy (Filomeni et al., 2015) and the activation of nuclear factor-E2-related factor 2 (Nrf2), by controlling cell redox homeostasis through the production/ recycling of the intracellular antioxidant glutathione (Calabrese et al., 2010; Johnson and Johnson, 2015).

Previous studies indicated that CLA improved systemic antioxidant and detoxifying defences via the activation of the Nrf2 pathway (Mollica et al., 2014; Bergamo et al., 2016). It is possible to hypothesize that its dietary supplementation might alleviate age-dependent neurodegenerative signs as showed in neuropsychiatric lupus old/diseased MRL/MpJ-Faslpr mice, considered an animal model of depression because of the spontaneous development of depressive-like behavior and autoimmune/oxidative stress signs (Monaco et al., 2018; Cigliano et al., 2019). In this study, mice (20- to 22-weeks-old) fed for five weeks with a daily supplementation of synthetic CLA mixture displayed a reduction of all pathological features in the brain when compared to young mice or healthy controls. This finding indicates a preventive effect of CLA against age-associated neuronal injury and hyper-activation of oxidative stress-activated compensatory mechanisms (Monaco et al., 2018).

An altered phospholipid (PL) metabolism may be associated with the loss of synapses and neurons, the formation of senile plaques and neurofibrillary tangles in AD (Pettegrew, 1989; Farooqui and Horrocks, 1994) and the decreased membrane fluidity. All these factors may be associated with functional and degenerative changes in the brain (Erin et al., 1986). One of the CLA functions is to alter, mostly decreasing, prostaglandin formation in a tissue-specific manner (Whigham et al., 2001; Belury, 2002; Whigham et al., 2002). Arachidonic acid (ARA, 20:4 $n-6)$, the principal FA esterified in sn-2 position of PL, can be specifically cleaved by phospholipases A2 (PLA2) (Dennis, 1987; Glaser et al., 1990; Wightman and Dallob, 1990; Farooqui et al., 2000) and converted into its inflammatory metabolite, prostaglandins G2 (PGE2), by cyclooxygenases (COX) enzyme (Miyamoto et al., 1976; Van der Ouderaa et al., 1977; Pagels et al., 1983; Tanaka et al., 1987; Ujihara et al., 1988). However, in the brain, ARA is mainly reincorporated into PLs (Rapoport, 1999; Leslie, 2004), through which can modulate neuronal function by various mechanisms (Katsuki and Okuda, 1995; Farooqui et al., 1997). Thus, regulation of PLA2 activity is important to maintain basal levels of ARA, lysophospholipids and to perform normal brain function (Farooqui et al., 2000; Phillis and O'Regan, 2004). The reduction of PLA2 activity in the brain may be involved in neuronal degeneration (Gattaz et al., 1995; Ross et al., 1998; Schaeffer et al., 2010). In cholinergic neurons, for instance, PLA2 controls the breakdown of phosphatidylcholine to produce choline for acetylcholine synthesis, and may contribute to the cholinergic deficit observed in AD (Blusztajn and Wurtman, 1983; Blusztajn et al., 1987). To date, a few studies concerning the effects of CLA on the activity and expression of PLA2 in in vivo tissues, especially in the brain, are available (Akdis et al., 2000; Eder et al., 2003; Ringseis et al., 2006; Stachowska et al., 2007). In the hippocampus of Wistar rats fed with a diet high in CLA, the mRNA levels of pla2 were increased together with the augmented enzymatic activity of PLA2 enzyme, and a potential correlation with memory improvement was observed (Gama et al., 2015).

These discrepant results in the literature suggest the importance of more studies aimed at a precise explanation of the relationship between PL metabolism and cognition. Animal models and clinical studies suggested that the activity and gene expression of PLA2 may involve the activation of PPARs (Kummer and Heneka, 2008). In fact, while especially PPAR $\gamma$ has been implicated in neural cell differentiation and death, as well as in inflammation and neurodegeneration in astrocytes (Combs et al., 2000; Heneka et al., 2000; Daynes and Jones, 2002; Xu and Drew, 2007; Bernardo and Minghetti, 2008), PPARa is involved in acetylcholine metabolism (Farioli-Vecchioli et al., 2001) and is related to excitatory amino acid neurotransmission and oxidative stress defence (Moreno et al., 2004). Interestingly, Sergeeva et al. showed that the expression of PLA2 was inhibited by PPARa and $\operatorname{PPAR}_{\gamma}$ agonists in naive astrocytes, but was increased by $\operatorname{PPAR}_{\gamma}$ activation in lipopolysaccharide (LPS)stimulated astrocytes (Sergeeva et al., 2010). Thus, CLAinduced enhancement of PLA2 gene expression may be mediated by the activation of PPAR $\gamma$ in the brain and might depend on the inflammatory status of the tissue (Gama et al., 2015).

There are few studies examining the mechanisms of CLA modulation of eicosanoids in the brain (Nakanishi et al., 2003). A reduction of ARA-derived eicosanoids by CLA is explained by the inhibition of the level of mRNA, protein, or activity of the COX-1 constitutive enzyme and/or the COX-2 inducible form (Bulgarella et al., 2001). COX-2 mRNA is elevated in the brain (Kaufmann et al., 1996; Yasojima et al., 1999) and is associated with inflammatory responses induced by stimuli including cytokines, tumor promoters, and growth factors (Seibert et al., 1995; Cao et al., 1996). Notably, CLA supplementation in maternal diet during pregnancy significantly reduced PGE2 levels in the cerebrum of mice at weaning, an effect that seems to persist until adulthood. CLA probably mitigates the toxic impact of $\beta$-amyloid in neurons by decreasing amyloid precursor protein gene expression and its holoprotein synthesis (Mattson et al., 1992; Lee et al., 1999; Melchor et al., 2000).

In female X-linked adrenoleukodystrophy patients, CLA exerted anti-neuroinflammatory activity (Cappa et al., 2012). In fact, changes in FA profile, especially in CLA incorporation, resulted in improved somatosensory evoked potentials and reduced IL-6 levels in CSF (Cappa et al., 2012). In addition, 
CLA crosses the human placenta to the fetus (Martin et al., 2000; Elias and Innis, 2001), is present in small amounts in human milk (McGuire et al., 1997), and is incorporated into infant plasma lipids (Innis and King, 1999). In the progeny of rat dams fed with goat milk containing CLA, the anxiety-like behavior was reduced, physical growth ameliorated and cortical electrical activity improved, demonstrating the importance of CLA on neonatal development and health (Soares et al., 2013). Thus, CLA may favor the neurodevelopment occurring during the embryonic phase and the initial phases of life (Muller et al., 2015). Queiroz et al. reported that maternal supplementation with different CLA concentrations (1\% and 3\%) during gestation and lactation in rats positively affected neurodevelopment by anticipating reflex maturation and improving working memory in the offspring. These effects might be indirect or through some metabolites since CLA was found in the brain only in trace amounts (Queiroz et al., 2019).

CLA can also exert beneficial effects on fat deposition and body weight and might facilitate decreased food intake and increased energy expenditure (Wang and Jones, 2004; SalasSalvado et al., 2006). To better elucidate the mechanism of the actions of exogenous CLA administration on the expression of hypothalamic neuropeptides known to regulate food intake, a group of researchers demonstrated that direct intracerebroventricular administration of CLA in rats inhibited appetite regulation, which was related with the decreased expression of the orexigenic neuropeptides $\mathrm{Y}$ (NPY) and agouti-related protein (AgRP) (Cao et al., 2007). Remarkably, PPAR $\alpha$ activation has been shown to produce satiety and reduces body weight gain in wild-type mice, but not in mice deficient in PPARa (Fu et al., 2003).

\section{Effects of Conjugated Linoleic Acid on Brain Cells in vitro}

Molecular mechanisms underlying the effects of CLA in the CNS were studied in different neural cell culture models. Astrocytes represent the most abundant type of glial cells and are responsible for a large variety of functions in the healthy CNS, including synaptogenesis, neuronal transmission and synaptic plasticity. Astrocytes also participate in immune and inflammatory responses and produce a wide range of factors, such as cytokines or chemokines that contribute to the inflammatory state of the CNS after injury or during neurodegenerative diseases (Colombo and Farina, 2016).

CLA induces a decrease in inflammatory factors in primary human astrocyte culture, suggesting a potential nutritional role in modulating astrocyte inflammatory response. Both $c 9, \mathrm{t} 11$ and $t 10, c 12$ isomers determine a downregulation of proinflammatory cytokine expression, such as tumor necrosis factor- $\alpha$ (TNF- $\alpha$ ), interleukin-1 $\beta$ (IL-1 $\beta$ ), and RANTES (regulated upon activation, normal $\mathrm{T}$ cell expressed and secreted), but only t10,c12 decreases ARA production. Interestingly, CLA exerts anti-inflammatory activity in astrocytes modifying FA metabolism as suggested by the increase of the 22:6/20:5 ratio (Saba et al., 2019), indicating an increased peroxisomal $\beta$-oxidation induced by PPARa.
In $\mathrm{AD}$, amyloid precursor protein (APP) cleavage by $\beta$-secretase (BACE1) generates $\beta$-amyloid peptide $(A \beta)$ that accumulates and form neurotoxic plaques outside the cells. Alternative processing of APP by a-secretase generates soluble $\mathrm{APPa}$ that has neurotrophic and neuroprotective properties. Calpain is a Ca2+-dependent protease which activity is dysregulated in $\mathrm{AD}$, causing an increase of BACE1 expression, tau phosphorylation, oxidative stress and other excitotoxicity assaults (Mahaman et al., 2019).

CLA has been proposed as an adjuvant for the treatment and the prevention of $\mathrm{AD}$ since it may control the abnormal processing of APP. In the human neuroblastoma cell line $\mathrm{SH}$ SY5Y, CLA induces a decrease of BACE1 expression and an increase of the extracellular secretion of soluble $\mathrm{APP} \alpha$ but does not affect the levels of APP. These effects of CLA are mediated by PPAR $\gamma$ activation (Li et al., 2011). Moreover, CLA acts as a potent and selective $\mu$-calpain inhibitor as reported by Lee and collaborators (Lee et al., 2013) that showed a neuroprotective effect of CLA against A $\beta$ and ROS-induced toxicity in SH-SY5Y cells. Moreover, CLA decreased the levels of proapoptotic proteins and tau phosphorylation and was able to prevent $\mathrm{A} \beta$ oligomerization and fibrillation.

CLA exerts a neuroprotective effect even in glutamate excitotoxicity in primary culture of rodent cortical neurons. Joo and Park showed inhibition of glutamate- and NMDAinduced cell death by a high concentration of CLA $(500 \mu \mathrm{M})$ in cultured rat cortical neurons (Joo and Park, 2003). On the other hand, Hunt et al. more recently observed similar effects, but at CLA concentration likely achieved by dietary supplementation. In fact, $30 \mu \mathrm{M} c 9, \mathrm{t} 11$ protects mouse cortical neurons from glutamate-induced excitotoxic death and increases levels of the anti-apoptotic BCL-2 protein, while $\mathrm{t} 10, \mathrm{c} 12$ isomer has no significant effect (Hunt et al., 2010).

Neural stem cells (NSC) and neural precursor cells (NPC) are self-renewing, multipotent cells that give rise to neurons and glial cells during development of the CNS, but continuously generate functional neurons in specific brain regions throughout life. c9,t11 promotes proliferation in neurospheres derived from rat NPC and increases cyclin D1 expression, while the isomer t10,c12 had the opposite effect (Wang et al., 2011). Moreover, treatment with c9,t11 promotes neuronal differentiation of rat NSC, increasing Tuj-1-positive cells. This effect is due in part to the increase of the bHLH transcription factor HES6 expression (Okui et al., 2011).

Several data suggest that also in the brain some of the effects exerted by CLA can be ascribed to its activation of PPAR $a$. In fact, we have previously shown that PPARa activation by synthetic agonists increased PEA and OEA biosynthesis, as we also showed in liver and muscle in vivo (Melis et al., 2013a; Trinchese et al., 2018; Trinchese et al., 2020).

In unpublished experiments, we evaluated the impact of CLA isomers or the mixture of both isomers, compared to synthetic (WY14643) and endogenous (FA) ligands or antagonist (MK886) of PPARa, on FA metabolism and biosynthesis of endogenous PPARa ligands OEA and PEA in midbrain slices. Our unpublished data showed that CLA is able to increase OEA and PEA levels in rat midbrain slices incubated for $60 \mathrm{~min}$ 

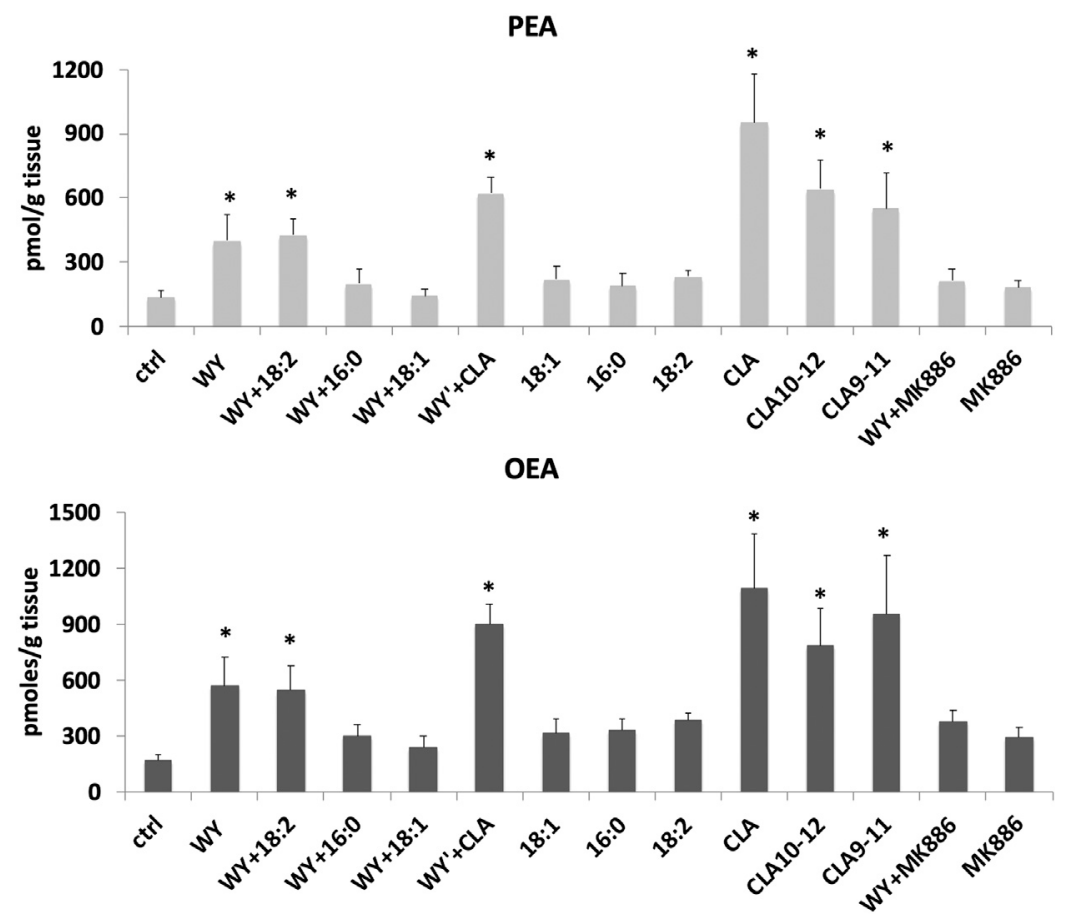

FIGURE 1 | Concentrations of palmitoylethanolamide (PEA) and oleoylethanolamide (OEA) analyzed by LC-MS as described in (Piras et al., 2015), in rat horizontal slices containing the midbrain incubated for $1 \mathrm{~h}$ with $100 \mu \mathrm{M}$ of synthetic and endogenous ligands of PPARa or their vehicle: agonist WY14643 (WY), oleic acid (18:1), palmitic acid (16:0), linoleic acid (18:2), c9-t11, t10-c12, and a mixture of both CLA isomers (CLA), or PPAR antagonist (MK886). Error bars represent SD; $n=6$. * denote significant differences $(p<0.05)$, vs. control (one-way ANOVA).

with $100 \mu \mathrm{M}$ of CLA mixture or pure $\mathrm{c} 9, \mathrm{t} 11$ and $\mathrm{t} 10 \mathrm{c} 12$ isomers (Figure 1). In addition, gavage-treated mice, with a single dose $(90 \mu \mathrm{g} / 10 \mathrm{~g}$ of body weight) of CLA or olive oil (Ctrl), fed a standard diet, similarly showed an increase of OEA levels in the hypothalamus (Figure 2).

Thus, our data strongly suggest that CLA exerts its activity, at least in part, via PPARa in brain tissues similarly to peripheral tissues. What are the potential implications of CLA activation of PPARa in the brain? Does it play a synergistic role with those exerted in peripheral tissues or may have further potential benefits? This point is quite relevant, given the pleiotropic effects of PPARa activation in the brain.

\section{Effect of Peroxisome Proliferator Activated Receptor Alpha in Brain}

PPARa displays a specific pattern of expression in the CNS, with higher levels in thalamic, mesencephalic and cranial motor nuclei, the reticular formation and the large motoneurons of the spinal cord and lower levels in the amygdala, prefrontal cortex, nucleus accumbens, ventral tegmental area and substantia nigra pars compacta (Moreno et al., 2004; Fidaleo et al., 2014; Warden et al., 2016). PPARa is also expressed by ependymal and astroglial cells, but not by oligodendrocytes (Moreno et al., 2004). Interest in the role of PPARa in the CNS has been fueled by the evidence that these nuclear receptors regulate a wide range of physiological functions in neuronal and glial cells, and might play a role in higher brain functions including memory consolidation and modulation of pain perception (Fidaleo et al., 2014). In this regard, it is noteworthy that the neuronal effects of PPARa agonists cannot only be explained through transcriptional

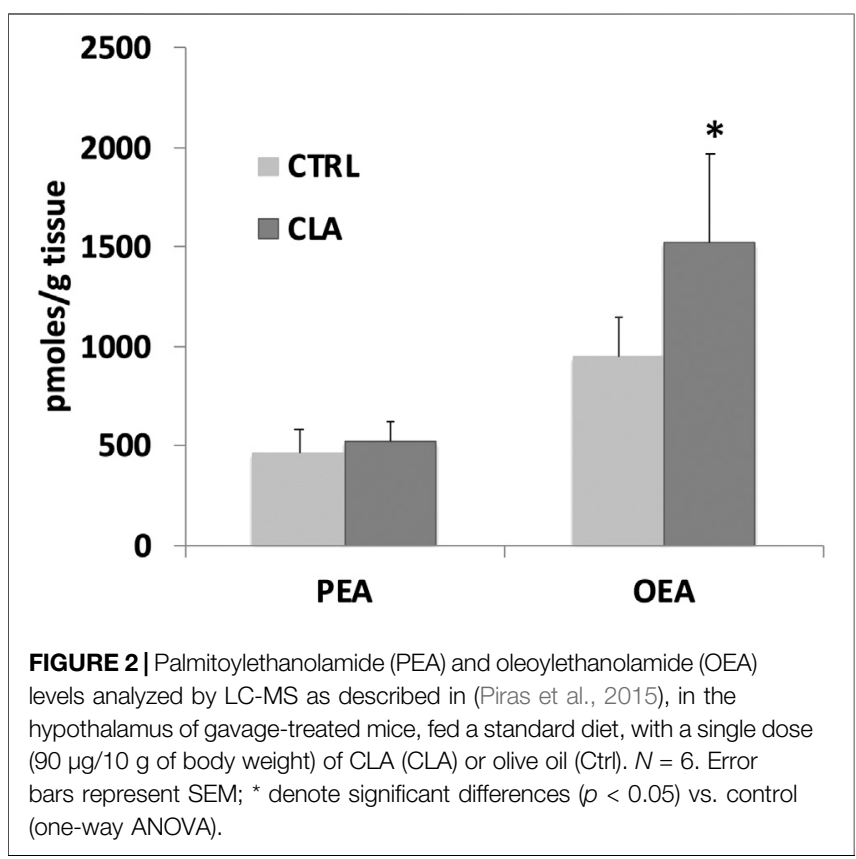


effects canonically ascribed to PPAR $a$ activation but also via rapid non-genomic mechanisms (Melis and Pistis, 2014; Pistis and Muntoni, 2017). Unlike genomic effects, which occur with a time lag of minutes to hours and days, these events take place over a very rapid time frame (i.e., seconds to a few minutes). This timescale is considered too rapid to be attributed to the biosynthesis of mRNA or proteins and is often unaffected by inhibitors of transcription or translation. Solid evidence that PPARa exerts rapid non-genomic effects also derives from the platelets, anucleate cells, where the PPARa ligands fibrates display antiaggregant effects by binding to and repressing $\mathrm{PKC} \alpha$, increasing intracellular levels of cAMP levels (Ali et al., 2009) and inhibiting ADP-stimulated platelet activation (Unsworth et al., 2018).

In the brain, non-genomic actions have been described in the cross-talk between PPAR $\alpha$ and nicotinic acetylcholine receptors (nAChRs) (Melis and Pistis, 2014). In midbrain dopamine neurons, a7nAChRs-induced $\mathrm{Ca}^{2+}$ influx triggers the synthesis of endogenous PPARa ligands which, in turn, activate PPAR $a$ to induce phosphorylation of $\beta 2$ subunits of a4 $\beta 22^{\star}$ nAChRs (Melis et al., 2010; Melis et al., 2013b). This interaction is hypothesized to serve as negative feedback to fine-tune the activity of nicotinic cholinergic transmission in the dopamine system, as activation of low-affinity a $7 \mathrm{nAChRs}$ by an excessive cholinergic tone negatively regulates either number and/or function of high affinity $\beta 2^{\star} n A C h R s$. Consistently, a PPARa antagonist prevents the inhibitory effects of an a $\mathrm{nAChR}$ agonist on nicotine reward in a mouse conditioned place preference paradigm, suggesting that $a 7 \mathrm{nAChR}$ activation attenuates nicotine place preference via a PPARa-dependent mechanism (Jackson et al., 2017). Accordingly, an $\alpha 7 \mathrm{nAChR}$ agonist prevents nicotine stimulating effects on spontaneous locomotor activity in mice, a condition in which the activation of $\beta 2^{\star} n A C h R s$ expressed on dopamine cells is necessary (Picciotto et al., 1998) and of PPARa sufficient (Melis and Pistis, unpublished data). Dysregulation of dopamineacetylcholine interplay occurring in pathological conditions such as stress, drug addiction, schizophrenia and depression, might benefit from PPAR $a$ activation (Melis and Pistis, 2014). Such PPAR $\alpha$-acetylcholine interaction also takes place in other brain areas receiving strong impact of cholinergic inputs such as the sensorimotor cortex (Puligheddu et al., 2013; Puligheddu et al., 2017). These findings provided the rationale for using PPARa ligands, i.e., the clinically approved fibrates, as add-on therapy in neurological disorders caused by a gain of function of nAChRs, such as in sleep-related hypermotor epilepsy (SHE, previously named nocturnal frontal lobe epilepsy, NFLE). Thus, the powerful actions exerted by PPAR $a$ via dual genomic and non-genomic mechanisms might contribute to strengthening the rationale for these nuclear receptors as a promising therapeutic target in the CNS, especially when considering that neuroinflammation appears to be involved in the pathophysiology of diverse psychiatric and neurological illnesses (Pistis and Muntoni, 2017; Tufano and Pinna, 2020). In particular, mounting evidence points to a relationship between neuroimmune function and neurodevelopment disorders such as autism and schizophrenia (Martínez-Gras et al., 2011; Chase et al., 2015; Gottfried and Bambini-Junior, 2018; Müller, 2018) as well as mood disorders (Scheggi et al., 2016; Pfau et al., 2018; Tufano and Pinna, 2020). In addition, it has been shown that fenofibrate reduces neuroinflammation, and blocks neurodegeneration in vivo (Esmaeili et al., 2016).

\section{CONCLUSION}

Intriguingly, while possible beneficial effects of CLA in peripheral tissues, probably mediated by PPAR $\alpha$ activation, have been the object of several studies in experimental animals (Trinchese et al., 2020), and humans (Murru et al., 2018), a few studies on possible positive actions in brain function and neuroinflammation through PPARa activation are available. Our findings that CLA increases PEA and OEA levels in peripheral tissues (Piras et al., 2015) and in mouse brain (Figure 2), and that this increase occurs in situ in the brain, similarly to PPARa agonists [Figure 1 and (Melis et al., 2013a)], supports the hypothesis that PPAR a activation induces PEA and OEA biosynthesis thereby sustaining PPAR $\alpha$ activation with a positive feedback mechanism.

Notably, CLA may indirectly, via sustaining OEA and PEA biosynthesis, activate receptors other than PPARa, like GPR119 and TRPV1, which are also implicated in metabolism regulation and anti-inflammatory activity, respectively (Godlewski et al., 2009; Ambrosino et al., 2013). Accordingly, increased dairy product intake is associated with improved cognitive function in humans (Crichton et al., 2012; Park and Fulgoni, 2013), whether these effects may be ascribed to CLA and/or other components in dairy products has not been elucidated yet. Thus, future studies should be devoted to investigating whether dietary CLA may positively modify brain metabolism, though PPAR $a$ activation, and thereby exert anti-inflammatory activity, particularly in the setting of neuropsychiatric disorders with neuroinflammatory bases.

\section{AUTHOR CONTRIBUTIONS}

EM, GC, and SB, conceived the topic of the review and organised the ms structure. CM, EM, GC, MM, MP, and SB performed and designed the experiments described in the unpublished data. VS reviewed the manuscript and contributed to the draft in particular on the in vitro literature. SB supervised the manuscript draft. All Authors contributed to the discussion and review and editing of the manuscript.

\section{ACKNOWLEDGMENTS}

This work was supported in part by a grant, with the code POC01_00069 from the Italian Ministry of the University and the Research within the program "Proof of Concept." 


\section{REFERENCES}

Akdis, M., Klunker, S., Schliz, M., Blaser, K., and Akdis, C. A. (2000). Expression of cutaneous lymphocyte-associated antigen on human CD4(+) and CD8(+) Th2 cells. Eur. J. Immunol. 30 (12), 3533-3541. doi:10.1002/1521-4141(2000012)30: 12<3533::AID-IMMU3533>3.0.CO;2-5

Alasnier, C., Berdeaux, O., Chardigny, J. M., and Sebedio, J. L. (2002). Fatty acid composition and conjugated linoleic acid content of different tissues in rats fed individual conjugated linoleic acid isomers given as triacylglycerols small star, filled. J. Nutr. Biochem. 13 (6), 337-345. doi:10.1016/s0955-2863(02)00176-6

Ali, F. Y., Armstrong, P. C., Dhanji, A. R., Tucker, A. T., Paul-Clark, M. J., Mitchell, J. A., et al. (2009). Antiplatelet actions of statins and fibrates are mediated by PPARs. Arterioscler. Thromb. Vasc. Biol. 29 (5), 706-711. doi:10.1161/ ATVBAHA.108.183160

Ambrosino, P., Soldovieri, M. V., Russo, C., and Taglialatela, M. (2013). Activation and desensitization of TRPV1 channels in sensory neurons by the PPARalpha agonist palmitoylethanolamide. Br. J. Pharmacol. 168 (6), 1430-1444. doi:10. 1111/bph.12029

Baes, M., and Aubourg, P. (2009). Peroxisomes, myelination, and axonal integrity in the CNS. Neuroscientist 15 (4), 367-379. doi:10.1177/1073858409336297

Banni, S., Angioni, E., Casu, V., Melis, M. P., Carta, G., Corongiu, F. P., et al. (1999). Decrease in linoleic acid metabolites as a potential mechanism in cancer risk reduction by conjugated linoleic acid. Carcinogenesis 20 (6), 1019-1024. doi:10. 1093/carcin/20.6.1019

Banni, S., Carta, G., Angioni, E., Murru, E., Scanu, P., Melis, M. P., et al. (2001). Distribution of conjugated linoleic acid and metabolites in different lipid fractions in the rat liver. J. Lipid Res. 42 (7), 1056-1061. doi:10.1007/ s11745-002-0956-5

Banni, S. (2002). Conjugated linoleic acid metabolism. Curr. Opin. Lipidol. 13 (3), 261-266. doi:10.1097/00041433-200206000-00005

Banni, S., Day, B. W., Evans, R. W., Corongiu, F. P., and Lombardi, B. (1995). Detection of conjugated diene isomers of linoleic-acid in liver lipids of rats fed a choline-devoid diet indicates that the diet does not cause lipoperoxidation. JNB (J. Nutr. Biochem.) 6 (5), 281-289. doi:10.1016/0955-2863(95)00049-6

Belury, M. A. (2002). Dietary conjugated linoleic acid in health: physiological effects and mechanisms of action. Annu. Rev. Nutr. 22, 505-531. doi:10.1146/ annurev.nutr.22.021302.121842

Belury, M. A., and KempaSteczko, A. (1997). Conjugated linoleic acid modulates hepatic lipid composition in mice. Lipids 32 (2), 199-204. doi:10.1007/s11745997-0025-0

Benjamin, S., Prakasan, P., Sreedharan, S., Wright, A. D., and Spener, F. (2015). Pros and cons of CLA consumption: an insight from clinical evidences. Nutr. Metab. 12, 4. doi:10.1186/1743-7075-12-4

Bergamo, P., Palmieri, G., Cocca, E., Ferrandino, I., Gogliettino, M., Monaco, A., et al. (2016). Adaptive response activated by dietary cis9, trans11 conjugated linoleic acid prevents distinct signs of gliadin-induced enteropathy in mice. Eur. J. Nutr. 55 (2), 729-740. doi:10.1007/s00394-015-0893-2

Bernardo, A., and Minghetti, L. (2008). Regulation of glial cell functions by PPARgamma natural and synthetic agonists. PPAR Res. 2008, 864140. doi:10.1155/ 2008/864140

Blusztajn, J. K., Liscovitch, M., and Richardson, U. I. (1987). Synthesis of acetylcholine from choline derived from phosphatidylcholine in a human neuronal cell line. Proc. Natl. Acad. Sci. USA 84 (15), 5474-5477. doi:10. 1073/pnas.84.15.5474

Blusztajn, J. K., and Wurtman, R. J. (1983). Choline and cholinergic neurons. Science 221 (4611), 614-620. doi:10.1126/science.6867732

Bulgarella, J. A., Patton, D., and Bull, A. W. (2001). Modulation of prostaglandin H synthase activity by conjugated linoleic acid (CLA) and specific CLA isomers. Lipids 36 (4), 407-412. doi:10.1007/s11745-001-0736-2

Calabrese, V., Cornelius, C., Dinkova-Kostova, A. T., Calabrese, E. J., and Mattson, M. P. (2010). Cellular stress responses, the hormesis paradigm, and vitagenes: novel targets for therapeutic intervention in neurodegenerative disorders. Antioxidants Redox Signal. 13 (11), 1763-1811. doi:10.1089/ars.2009.3074

Cao, C., Matsumura, K., Yamagata, K., and Watanabe, Y. (1996). Endothelial cells of the rat brain vasculature express cyclooxygenase- 2 mRNA in response to systemic interleukin-1 beta: a possible site of prostaglandin synthesis responsible for fever. Brain Res. 733 (2), 263-272. doi:10.1016/00068993(96)00575-6
Cao, Z. P., Wang, F., Xiang, X. S., Cao, R., Zhang, W. B., and Gao, S. B. (2007). Intracerebroventricular administration of conjugated linoleic acid (CLA) inhibits food intake by decreasing gene expression of NPY and AgRP. Neurosci. Lett. 418 (3), 217-221. doi:10.1016/j.neulet.2007.03.010

Cappa, M., Bizzarri, C., Petroni, A., Carta, G., Cordeddu, L., Valeriani, M., et al. (2012). A mixture of oleic, erucic and conjugated linoleic acids modulates cerebrospinal fluid inflammatory markers and improve somatosensorial evoked potential in X-linked adrenoleukodystrophy female carriers. J. Inherit. Metab. Dis. 35 (5), 899-907. doi:10.1007/s10545-011-9432-3

Carta, G., Murru, E., Manca, C., Serra, A., Mele, M., and Banni, S. (2019). Natural CLA-enriched lamb meat fat modifies tissue fatty acid profile and increases n-3 HUFA score in obese zucker rats. Biomolecules 9 (11), 751. doi:10.3390/ biom 9110751

Carta, G., Murru, E., Vargiu, R., Collu, M., Carta, M., Banni, S., et al. (2020). Essential fatty acids deficient diet modulates N-Acylethanolamide profile in rat's tissues. Prostaglandins Leukot. Essent. Fatty Acids 153, 102053. doi:10. 1016/j.plefa.2020.102053

Chase, K. A., Rosen, C., Gin, H., Bjorkquist, O., Feiner, B., Marvin, R., et al. (2015). Metabolic and inflammatory genes in schizophrenia. Psychiatr. Res. 225 (1-2), 208-211. doi:10.1016/j.psychres.2014.11.007

Churruca, I., Fernandez-Quintela, A., and Portillo, M. P. (2009). Conjugated linoleic acid isomers: differences in metabolism and biological effects. Biofactors 35 (1), 105-111. doi:10.1002/biof.13

Cigliano, L., Spagnuolo, M. S., Boscaino, F., Ferrandino, I., Monaco, A., Capriello, T., et al. (2019). Dietary supplementation with fish oil or conjugated linoleic acid relieves depression markers in mice by modulation of the Nrf2 pathway. Mol. Nutr. Food Res. 63 (21), e1900243. doi: $10.1002 / \mathrm{mnfr} .201900243$

Colombo, E., and Farina, C. (2016). Astrocytes: key regulators of neuroinflammation. Trends Immunol. 37 (9), 608-620. doi:10.1016/j.it.2016. 06.006

Combs, C. K., Johnson, D. E., Karlo, J. C., Cannady, S. B., and Landreth, G. E. (2000). Inflammatory mechanisms in Alzheimer's disease: inhibition of betaamyloid-stimulated proinflammatory responses and neurotoxicity by PPARgamma agonists. J. Neurosci. 20 (2), 558-567.

Crichton, G. E., Elias, M. F., Dore, G. A., and Robbins, M. A. (2012). Relation between dairy food intake and cognitive function: the Maine-Syracuse Longitudinal Study. Int. Dairy J. 22 (1), 15-23. doi:10.1016/j.idairyj.2011.08.001

Cullingford, T. E., Bhakoo, K., Peuchen, S., Dolphin, C. T., Patel, R., and Clark, J. B. (1998). Distribution of mRNAs encoding the peroxisome proliferator-activated receptor alpha, beta, and gamma and the retinoid $\mathrm{X}$ receptor alpha, beta, and gamma in rat central nervous system. J. Neurochem. 70 (4), 1366-1375. doi:10. 1046/j.1471-4159.1998.70041366.x

Daynes, R. A., and Jones, D. C. (2002). Emerging roles of PPARs in inflammation and immunity. Nat. Rev. Immunol. 2 (10), 748-759. doi:10.1038/nri912

Delerive, P., Fruchart, J. C., and Staels, B. (2001). Peroxisome proliferator-activated receptors in inflammation control. J. Endocrinol. 169 (3), 453-459. doi:10.1677/ joe. 0.1690453

den Hartigh, L. J. (2019). Conjugated linoleic acid effects on cancer, obesity, and atherosclerosis: a review of pre-clinical and human trials with current perspectives. Nutrients 11, 370. doi:10.3390/nu11020370

Dennis, E. A. (1987). Regulation of eicosanoid production: role of phospholipases and inhibitors. Nat. Biotechnol. 5, 1294-1300. doi:10.1038/nbt1287-1294

Di Biase, D., and Markus, A. (1998). Cleft lip and palate care in the UK: the CSAG report. Br. Dent. J. 185 (7), 320-321. doi:10.1038/sj.bdj.4809800

Douar, A. M., Mosser, J., Sarde, C. O., Lopez, J., Mandel, J. L., and Aubourg, P. (1994). X-linked adrenoleukodystrophy gene: identification of a candidate gene by positional cloning. Biomed. Pharmacother. 48 (5-6), 215-218. doi:10.1016/ 0753-3322(94)90135-x

Echeverria, F., Ortiz, M., Valenzuela, R., and Videla, L. A. (2016). Long-chain polyunsaturated fatty acids regulation of PPARs, signaling: relationship to tissue development and aging. Prostaglandins Leukot. Essent. Fatty Acids 114, 28-34. doi:10.1016/j.plefa.2016.10.001

Eder, K., Schleser, S., Becker, K., and Korting, R. (2003). Conjugated linoleic acids lower the release of eicosanoids and nitric oxide from human aortic endothelial cells. J. Nutr. 133 (12), 4083-4089. doi:10.1093/jn/133.12.4083

Elias, S. L., and Innis, S. M. (2001). Infant plasma trans, n-6, and n-3 fatty acids and conjugated linoleic acids are related to maternal plasma fatty acids, length of 
gestation, and birth weight and length. Am. J. Clin. Nutr. 73 (4), 807-814. doi:10.1093/ajen/73.4.807

Erin, A. N., Gorbunov, N. V., Brusovanik, V. I., Tyurin, V. A., and Prilipko, L. L. (1986). Stabilization of synaptic membranes by alpha-tocopherol against the damaging action of phospholipases. Possible mechanism of biological action of vitamin E. Brain Res. 398 (1), 85-90. doi:10.1016/0006-8993(86)91253-9

Esmaeili, M. A., Yadav, S., Gupta, R. K., Waggoner, G. R., Deloach, A., Calingasan, N. Y., et al. (2016). Preferential PPAR-alpha activation reduces neuroinflammation, and blocks neurodegeneration in vivo. Hum. Mol. Genet. 25 (2), 317-327. doi:10.1093/hmg/ddv477

Fa, M., Diana, A., Carta, G., Cordeddu, L., Melis, M. P., Murru, E., et al. (2005). Incorporation and metabolism of $\mathrm{c} 9, \mathrm{t} 11$ and $\mathrm{t} 10, \mathrm{c} 12$ conjugated linoleic acid (CLA) isomers in rat brain. Biochim. Biophys. Acta 1736 (1), 61-66. doi:10. 1016/j.bbalip.2005.06.010

Farioli-Vecchioli, S., Moreno, S., and Ceru, M. P. (2001). Immunocytochemical localization of acyl-CoA oxidase in the rat central nervous system. J. Neurocytol. 30 (1), 21-33. doi:10.1023/a:1011913223541

Farooqui, A. A., and Horrocks, L. A. (1994). Excitotoxicity and neurological disorders: involvement of membrane phospholipids. Int. Rev. Neurobiol. 36, 267-323. doi:10.1016/s0074-7742(08)60306-2

Farooqui, A. A., Ong, W. Y., Horrocks, L. A., and Farooqui, T. (2000). Brain cytosolic phospholipase A2: localization, role, and involvement in neurological diseases. Neuroscientist 6, 169-180. doi:10.1177/107385840000600308

Farooqui, A. A., Rosenberger, T. A., and Horrocks, L. A. (1997). Arachidonic acid, neurotrauma, and neurodegenerative diseases. Totowa, NJ: Humana Press Inc.

Ferdinandusse, S., Denis, S., Dacremont, G., and Wanders, R. A. (2003). Studies on the metabolic fate of $n-3$ polyunsaturated fatty acids. JLR (J. Lipid Res.) 44 (10), 1992-1997. doi:10.1194/jlr.M300223-JLR200

Ferdinandusse, S., Meissner, T., Wanders, R. J., and Mayatepek, E. (2002). Identification of the peroxisomal beta-oxidation enzymes involved in the degradation of leukotrienes. Biochem. Biophys. Res. Commun. 293 (1), 269-273. doi:10.1016/S0006-291X(02)00214-0

Fidaleo, M., Fanelli, F., Ceru, M. P., and Moreno, S. (2014). Neuroprotective properties of peroxisome proliferator-activated receptor alpha (PPARalpha) and its lipid ligands. Curr. Med. Chem. 21 (24), 2803-2821. doi:10.2174/ 0929867321666140303143455

Filomeni, G., De Zio, D., and Cecconi, F. (2015). Oxidative stress and autophagy: the clash between damage and metabolic needs. Cell Death Differ. 22 (3), 377-388. doi:10.1038/cdd.2014.150

Forman, B. M., Chen, J., and Evans, R. M. (1997). Hypolipidemic drugs, polyunsaturated fatty acids, and eicosanoids are ligands for peroxisome proliferator-activated receptors alpha and delta. Proc. Natl. Acad. Sci. USA 94 (9), 4312-4317. doi:10.1073/pnas.94.9.4312

Fu, J., Gaetani, S., Oveisi, F., Lo Verme, J., Serrano, A., Rodriguez De Fonseca, F., et al. (2003). Oleylethanolamide regulates feeding and body weight through activation of the nuclear receptor PPAR-alpha. Nature 425 (6953), 90-93. doi:10.1038/nature01921

Fu, J., Oveisi, F., Gaetani, S., Lin, E., and Piomelli, D. (2005). Oleoylethanolamide, an endogenous PPAR-alpha agonist, lowers body weight and hyperlipidemia in obese rats. Neuropharmacology 48 (8), 1147-1153. doi:10.1016/j.neuropharm. 2005.02.013

Gama, M. A., Raposo, N. R., Mury, F. B., Lopes, F. C., Dias-Neto, E., Talib, L. L., et al. (2015). Conjugated linoleic acid-enriched butter improved memory and up-regulated phospholipase A2 encoding-genes in rat brain tissue. J. Neural. Transm. 122 (10), 1371-1380. doi:10.1007/s00702-015-1401-9

Gattaz, W. F., Maras, A., Cairns, N. J., Levy, R., and Forstl, H. (1995). Decreased phospholipase A2 activity in Alzheimer brains. Biol. Psychiatr. 37 (1), 13-17. doi:10.1016/0006-3223(94)00123-K

Glaser, K. B., Asmis, R., and Dennis, E. A. (1990). Bacterial lipopolysaccharide priming of P388D1 macrophage-like cells for enhanced arachidonic acid metabolism. Platelet-activating factor receptor activation and regulation of phospholipase A2. J. Biol. Chem. 265 (15), 8658-8664.

Godlewski, G., Offertaler, L., Wagner, J. A., and Kunos, G. (2009). Receptors for acylethanolamides-GPR55 and GPR119. Prostag. Other Lipid Mediat. 89 (3-4), 105-111. doi:10.1016/j.prostaglandins.2009.07.001

Gottfried, C., and Bambini-Junior, V. (2018). Insights into the relationship of the immune system with neurodevelopmental and psychiatric disorders. Neuroimmunomodulation 25 (5, 6), 243-245. doi:10.1159/000496180
Gottlicher, M., Demoz, A., Svensson, D., Tollet, P., Berge, R. K., and Gustafsson, J. A. (1993). Structural and metabolic requirements for activators of the peroxisome proliferator-activated receptor. Biochem. Pharmacol. 46 (12), 2177-2184. doi:10.1016/0006-2952(93)90607-x

Gottlicher, M., Widmark, E., Li, Q., and Gustafsson, J. A. (1992). Fatty acids activate a chimera of the clofibric acid-activated receptor and the glucocorticoid receptor. Proc. Natl. Acad. Sci. USA 89 (10), 4653-4657. doi:10.1073/pnas.89.10. 4653

Guzman, M., Lo Verme, J., Fu, J., Oveisi, F., Blazquez, C., and Piomelli, D. (2004). Oleoylethanolamide stimulates lipolysis by activating the nuclear receptor peroxisome proliferator-activated receptor alpha (PPAR-alpha). J. Biol. Chem. 279 (27), 27849-27854. doi:10.1074/jbc.M404087200

Hall, M. G., Quignodon, L., and Desvergne, B. (2008). Peroxisome proliferatoractivated receptor beta/delta in the brain: facts and hypothesis. PPAR Res. 2008, 780452. doi:10.1155/2008/780452

Hamilton, J. A., Hillard, C. J., Spector, A. A., and Watkins, P. A. (2007). Brain uptake and utilization of fatty acids, lipids and lipoproteins: application to neurological disorders. J. Mol. Neurosci. 33 (1), 2-11. doi:10.1007/s12031-0070060-1

Heneka, M. T., Klockgether, T., and Feinstein, D. L. (2000). Peroxisome proliferator-activated receptor-gamma ligands reduce neuronal inducible nitric oxide synthase expression and cell death in vivo. J. Neurosci. 20 (18), 6862-6867. doi:10.1523/JNEUROSCI.20-18-06862.2000

Hunt, W. T., Kamboj, A., Anderson, H. D., and Anderson, C. M. (2010). Protection of cortical neurons from excitotoxicity by conjugated linoleic acid. J. Neurochem. 115 (1), 123-130. doi:10.1111/j.1471-4159.2010.06908.x

Iannone, A., Petroni, A., Murru, E., Cordeddu, L., Carta, G., Melis, M. P., et al. (2009). Impairment of 8-iso-PGF(2ALPHA) isoprostane metabolism by dietary conjugated linoleic acid (CLA). Prostaglandins Leukot. Essent. Fatty Acids 80 (5, 6), 279-287. doi:10.1016/j.plefa.2009.02.008

Innis, S. M., and King, D. J. (1999). Trans Fatty acids in human milk are inversely associated with concentrations of essential all-cis n-6 and n-3 fatty acids and determine trans, but not $\mathrm{n}-6$ and $\mathrm{n}-3$, fatty acids in plasma lipids of breast-fed infants. Am. J. Clin. Nutr. 70 (3), 383-390. doi:10.1093/ajen/70.3.383

Jackson, A., Bagdas, D., Muldoon, P. P., Lichtman, A. H., Carroll, F. I., Greenwald, M., et al. (2017). In vivo interactions between $\alpha 7$ nicotinic acetylcholine receptor and nuclear peroxisome proliferator-activated receptor- $\alpha$ : implication for nicotine dependence. Neuropharmacology 118, 38-45. doi:10.1016/j. neuropharm.2017.03.005

Johnson, D. A., and Johnson, J. A. (2015). Nrf2--a therapeutic target for the treatment of neurodegenerative diseases. Free Radic. Biol. Med. 88 (Pt B), 253-267. doi:10.1016/j.freeradbiomed.2015.07.147

Joo, N. E., and Park, C. S. (2003). Inhibition of excitotoxicity in cultured rat cortical neurons by a mixture of conjugated linoleic acid isomers. Pharmacol. Res. 47 (4), 305-310. doi:10.1016/s1043-6618(03)00008-2

Katsuki, H., and Okuda, S. (1995). Arachidonic acid as a neurotoxic and neurotrophic substance. Prog. Neurobiol. 46 (6), 607-636. doi:10.1016/03010082(95)00016-o

Kaufmann, W. E., Worley, P. F., Pegg, J., Bremer, M., and Isakson, P. (1996). COX2 , a synaptically induced enzyme, is expressed by excitatory neurons at postsynaptic sites in rat cerebral cortex. Proc. Natl. Acad. Sci. USA 93 (6), 2317-2321. doi:10.1073/pnas.93.6.2317

Kennedy, A., Chung, S., LaPoint, K., Fabiyi, O., and McIntosh, M. K. (2008). Trans10, Cis-12 conjugated linoleic acid antagonizes ligand-dependent PPAR gamma activity in primary cultures of human adipocytes. J. Nutr. 138 (3), 455-461. doi:10.1093/jn/138.3.455

Korbecki, J., Bobinski, R., and Dutka, M. (2019). Self-regulation of the inflammatory response by peroxisome proliferator-activated receptors. Inflamm. Res. 68 (6), 443-458. doi:10.1007/s00011-019-01231-1

Krey, G., Braissant, O., L’Horset, F., Kalkhoven, E., Perroud, M., Parker, M. G., et al. (1997). Fatty acids, eicosanoids, and hypolipidemic agents identified as ligands of peroxisome proliferator-activated receptors by coactivator-dependent receptor ligand assay. Mol. Endocrinol. 11 (6), 779-791. doi:10.1210/mend. 11.6.0007

Kummer, M. P., and Heneka, M. T. (2008). PPARs in Alzheimer's disease. PPAR Res. 2008, 403896. doi:10.1155/2008/403896

Lee, E., Eom, J. E., Kim, H. L., Baek, K. H., Jun, K. Y., Kim, H. J., et al. (2013). Effect of conjugated linoleic acid, mu-calpain inhibitor, on pathogenesis of 
Alzheimer's disease. Biochim. Biophys. Acta 1831 (4), 709-718. doi:10.1016/j. bbalip.2012.12.003

Lee, R. K., Knapp, S., and Wurtman, R. J. (1999). Prostaglandin E2 stimulates amyloid precursor protein gene expression: inhibition by immunosuppressants. J. Neurosci. 19 (3), 940-947. doi:10.1523/JNEUROSCI.19-03-00940.1999

Leslie, C. C. (2004). Regulation of arachidonic acid availability for eicosanoid production. Biochem. Cell. Biol. 82 (1), 1-17. doi:10.1139/o03-080

Li, Y. C., Chen, Q., Wan, X. Z., Yang, X. L., Liu, X., and Zhong, L. (2011). Effects of conjugated linoleic acid on cleavage of amyloid precursor protein via PPARgamma. Neurol. Sci. 32 (6), 1095-1101. doi:10.1007/s10072-011-0711-4

Lin, X., Bo, J., Oliver, S. A., Corl, B. A., Jacobi, S. K., Oliver, W. T., et al. (2011). Dietary conjugated linoleic acid alters long chain polyunsaturated fatty acid metabolism in brain and liver of neonatal pigs. J. Nutr. Biochem. 22 (11), 1047-1054. doi:10.1016/j.jnutbio.2010.09.002

Mahaman, Y. A. R., Huang, F., Kessete Afewerky, H., Maibouge, T. M. S., Ghose, B., and Wang, X. (2019). Involvement of calpain in the neuropathogenesis of Alzheimer's disease. Med. Res. Rev. 39 (2), 608-630. doi:10.1002/med.21534

Martin, J. C., Gregoire, S., Siess, M. H., Genty, M., Chardigny, J. M., Berdeaux, O., et al. (2000). Effects of conjugated linoleic acid isomers on lipid-metabolizing enzymes in male rats. Lipids 35 (1), 91-98. doi:10.1007/s11745-000-0499-9

Martínez-Gras, I., Pérez-Nievas, B. G., García-Bueno, B., Madrigal, J. L. M., Andrés-Esteban, E., Rodríguez-Jiménez, R., et al. (2011). The antiinflammatory prostaglandin 15d-PGJ2 and its nuclear receptor PPARgamma are decreased in schizophrenia. Schizophr. Res. 128 (1-3), 15-22. doi:10.1016/j. schres.2011.01.018

Martins, S. V., Lopes, P. A., Alfaia, C. M., Ribeiro, V. S., Guerreiro, T. V., Fontes, C. M., et al. (2007). Contents of conjugated linoleic acid isomers in ruminantderived foods and estimation of their contribution to daily intake in Portugal. Br. J. Nutr. 98 (6), 1206-1213. doi:10.1017/S0007114507781448

Mattson, M. P., Cheng, B., Davis, D., Bryant, K., Lieberburg, I., and Rydel, R. E. (1992). beta-Amyloid peptides destabilize calcium homeostasis and render human cortical neurons vulnerable to excitotoxicity. J. Neurosci. 12 (2), 376-389.

McGuire, M. K., Park, Y., Behre, R. A., Harrison, L. Y., Shultz, T. D., and McGuire, M. A. (1997). Conjugated linoleic acid concentrations of human milk and infant formula. Nutr. Res. 17, 1277-1283.

Melchor, J. P., McVoy, L., and Van Nostrand, W. E. (2000). Charge alterations of E22 enhance the pathogenic properties of the amyloid beta-protein. J. Neurochem. 74 (5), 2209-2212. doi:10.1046/j.1471-4159.2000.0742209.x

Mele, M. C., Cannelli, G., Carta, G., Cordeddu, L., Melis, M. P., Murru, E., et al. (2013). Metabolism of c9,t11-conjugated linoleic acid (CLA) in humans. Prostaglandins Leukot. Essent. Fatty Acids 89 (2, 3), 115-119. doi:10.1016/j. plefa.2013.05.005

Melis, M., Carta, S., Fattore, L., Tolu, S., Yasar, S., Goldberg, S. R., et al. (2010). Peroxisome proliferator-activated receptors-alpha modulate dopamine cell activity through nicotinic receptors. Biol. Psychiatr. 68 (3), 256-264. doi:10. 1016/j.biopsych.2010.04.016

Melis, M., Carta, G., Pistis, M., and Banni, S. (2013a). Physiological role of peroxisome proliferator-activated receptors type alpha on dopamine systems. CNS Neurol. Disord. - Drug Targets 12 (1), 70-77. doi:10.2174/ 1871527311312010012

Melis, M., Scheggi, S., Carta, G., Madeddu, C., Lecca, S., Luchicchi, A., et al. (2013b). PPARalpha regulates cholinergic-driven activity of midbrain dopamine neurons via a novel mechanism involving alpha7 nicotinic acetylcholine receptors. J. Neurosci. 33 (14), 6203-6211. doi:10.1523/ JNEUROSCI.4647-12.2013

Melis, M., and Pistis, M. (2014). Targeting the interaction between fatty acid ethanolamides and nicotinic receptors: therapeutic perspectives. Pharmacol. Res. 86, 42-49. doi:10.1016/j.phrs.2014.03.009

Miyamoto, T., Ogino, N., Yamamoto, S., and Hayaishi, O. (1976). Purification of prostaglandin endoperoxide synthetase from bovine vesicular gland microsomes. J. Biol. Chem. 251 (9), 2629-2636.

Mollica, M. P., Trinchese, G., Cavaliere, G., De Filippo, C., Cocca, E., Gaita, M., et al. (2014). c9,t11-Conjugated linoleic acid ameliorates steatosis by modulating mitochondrial uncoupling and Nrf2 pathway. J. Lipid Res. 55 (5), 837-849. doi:10.1194/jlr.M044032

Monaco, A., Ferrandino, I., Boscaino, F., Cocca, E., Cigliano, L., Maurano, F., et al. (2018). Conjugated linoleic acid prevents age-dependent neurodegeneration in a mouse model of neuropsychiatric lupus via the activation of an adaptive response. J. Lipid Res. 59 (1), 48-57. doi:10.1194/jlr.M079400

Moreno, S., Farioli-Vecchioli, S., and Ceru, M. P. (2004). Immunolocalization of peroxisome proliferator-activated receptors and retinoid $\mathrm{X}$ receptors in the adult rat CNS. Neuroscience 123 (1), 131-145. doi:10.1016/j.neuroscience.2003. 08.064

Moya-Camarena, S. Y., Vanden Heuvel, J. P., Blanchard, S. G., Leesnitzer, L. A., and Belury, M. A. (1999). Conjugated linoleic acid is a potent naturally occurring ligand and activator of PPARalpha. J. Lipid Res. 40 (8), 1426-1433.

Muller, C. P., Reichel, M., Muhle, C., Rhein, C., Gulbins, E., and Kornhuber, J. (2015). Brain membrane lipids in major depression and anxiety disorders. Biochim. Biophys. Acta 1851 (8), 1052-1065. doi:10.1016/j.bbalip.2014.12.014

Müller, N. (2018). Inflammation in schizophrenia: pathogenetic aspects and therapeutic considerations. Schizophr. Bull. 44 (5), 973-982. doi:10.1093/ schbul/sby024

Murru, E., Carta, G., Cordeddu, L., Melis, M. P., Desogus, E., Ansar, H., et al. (2018). Dietary conjugated linoleic acid-enriched cheeses influence the levels of circulating n-3 highly unsaturated fatty acids in humans. Int. J. Mol. Sci. 19 (6), 1730. doi:10.3390/ijms19061730

Nakanishi, T., Koutoku, T., Kawahara, S., Murai, A., and Furuse, M. (2003). Dietary conjugated linoleic acid reduces cerebral prostaglandin E(2) in mice. Neurosci. Lett. 341 (2), 135-138. doi:10.1016/s0304-3940(03)00189-7

Okui, T., Hashimoto, M., Katakura, M., and Shido, O. (2011). Cis-9,trans-11conjugated linoleic acid promotes neuronal differentiation through regulation of Hes6 mRNA and cell cycle in cultured neural stem cells. Prostaglandins Leukot. Essent. Fatty Acids 85 (3, 4), 163-169. doi:10.1016/j.plefa.2011.06.001

Pagels, W. R., Sachs, R. J., Marnett, L. J., Dewitt, D. L., Day, J. S., and Smith, W. L. (1983). Immunochemical evidence for the involvement of prostaglandin $\mathrm{H}$ synthase in hydroperoxide-dependent oxidations by ram seminal vesicle microsomes. J. Biol. Chem. 258 (10), 6517-6523.

Park, K. M., and Fulgoni, V. L., 3rd (2013). The association between dairy product consumption and cognitive function in the National Health and Nutrition Examination Survey. Br. J. Nutr. 109 (6), 1135-1142. doi:10.1017/ S0007114512002905

Paterson, L. J., Weselake, R. J., Mir, P. S., and Mir, Z. (2002). Positional distribution of CLA in TAG of lamb tissues. Lipids 37 (6), 605-611. doi:10.1007/s11745-0020939-6

Pettegrew, J. W. (1989). Molecular insights into Alzheimer's disease. Ann. N. Y. Acad. Sci. 568, 5-28. doi:10.1111/j.1749-6632.1989.tb12486.x

Pfau, M. L., Menard, C., and Russo, S. J. (2018). Inflammatory mediators in mood disorders: therapeutic opportunities. Annu. Rev. Pharmacol. Toxicol. 58, 411-428. doi:10.1146/annurev-pharmtox-010617-052823

Phillis, J. W., and O'Regan, M. H. (2004). A potentially critical role of phospholipases in central nervous system ischemic, traumatic, and neurodegenerative disorders. Brain Res Brain Res Rev 44 (1), 13-47. doi:10. 1016/j.brainresrev.2003.10.002

Picciotto, M. R., Zoli, M., Rimondini, R., Lena, C., Marubio, L. M., Pich, E. M., et al. (1998). Acetylcholine receptors containing the beta2 subunit are involved in the reinforcing properties of nicotine. Nature 391 (6663), 173-177.

Piras, A., Carta, G., Murru, E., Lopes, P. A., Martins, S. V., Prates, J. A., et al. (2015). Effects of dietary CLA on n-3 HUFA score and N-acylethanolamides biosynthesis in the liver of obese Zucker rats. Prostaglandins Leukot. Essent. Fatty Acids 98, 15-19. doi:10.1016/j.plefa.2015.04.004

Pistis, M., and Muntoni, A. L. (2017). "Roles of N-acylethanolamines in brain functions and neuropsychiatric diseases," in Endocannabinoids and lipid mediators in brain functions. Editor M. Melis (Cham, Switzerland: Springer International Publishing)), 319-346.

Poulos, A., Gibson, R., Sharp, P., Beckman, K., and Grattan-Smith, P. (1994). Very long chain fatty acids in X-linked adrenoleukodystrophy brain after treatment with Lorenzo's oil. Ann. Neurol. 36 (5), 741-746. doi:10.1002/ana. 410360509

Puligheddu, M., Melis, M., Pillolla, G., Milioli, G., Parrino, L., Terzano, G. M., et al. (2017). Rationale for an adjunctive therapy with fenofibrate in pharmacoresistant nocturnal frontal lobe epilepsy. Epilepsia 58 (10), 1762-1770. doi:10.1111/epi.13863

Puligheddu, M., Pillolla, G., Melis, M., Lecca, S., Marrosu, F., De Montis, M. G., et al. (2013). PPAR-alpha agonists as novel antiepileptic drugs: preclinical findings. PloS One 8 (5), e64541. doi:10.1371/journal.pone.0064541 
Queiroz, M. P., Lima, M. D. S., Barbosa, M. Q., de Melo, M., Bertozzo, C., de Oliveira, M. E. G., et al. (2019). Effect of conjugated linoleic acid on memory and reflex maturation in rats treated during early life. Front. Neurosci. 13, 370. doi:10.3389/fnins.2019.00370

Raff, M., Tholstrup, T., Basu, S., Nonboe, P., Sorensen, M. T., and Straarup, E. M. (2008). A diet rich in conjugated linoleic acid and butter increases lipid peroxidation but does not affect atherosclerotic, inflammatory, or diabetic risk markers in healthy young men. J. Nutr. 138 (3), 509-514. doi:10.1093/jn/ 138.3.509

Rapoport, S. I. (1999). In vivo fatty acid incorporation into brain phospholipids in relation to signal transduction and membrane remodeling. Neurochem. Res. 24 (11), 1403-1415. doi:10.1023/a:1022584707352

Reddy, J. K., and Hashimoto, T. (2001). Peroxisomal beta-oxidation and peroxisome proliferator-activated receptor alpha: an adaptive metabolic system. Annu. Rev. Nutr. 21, 193-230. doi:10.1146/annurev.nutr.21.1.193

Ricote, M., and Glass, C. K. (2007). PPARs and molecular mechanisms of transrepression. Biochim. Biophys. Acta Mol. Cell Biol. Lipids 1771 (8), 926-935. doi:10.1016/j.bbalip.2007.02.013

Ringseis, R., Muller, A., Herter, C., Gahler, S., Steinhart, H., and Eder, K. (2006). CLA isomers inhibit TNFalpha-induced eicosanoid release from human vascular smooth muscle cells via a PPARgamma ligand-like action. Biochim. Biophys. Acta 1760 (2), 290-300. doi:10.1016/j.bbagen. 2005.12.002

Riserus, U., Vessby, B., Arnlov, J., and Basu, S. (2004). Effects of cis-9,trans-11 conjugated linoleic acid supplementation on insulin sensitivity, lipid peroxidation, and proinflammatory markers in obese men. Am. J. Clin. Nutr. 80 (2), 279-283. doi:10.1093/ajcn/80.2.279

Rojo, A. I., McBean, G., Cindric, M., Egea, J., Lopez, M. G., Rada, P., et al. (2014). Redox control of microglial function: molecular mechanisms and functional significance. Antioxidants Redox Signal. 21 (12), 1766-1801. doi:10.1089/ars. 2013.5745

Ross, B. M., Moszczynska, A., Erlich, J., and Kish, S. J. (1998). Phospholipidmetabolizing enzymes in Alzheimer's disease: increased lysophospholipid acyltransferase activity and decreased phospholipase A2 activity. J. Neurochem. 70 (2), 786-793. doi:10.1046/j.1471-4159.1998.70020786.x

Saba, F., Sirigu, A., Pillai, R., Caria, P., Cordeddu, L., Carta, G., et al. (2019). Downregulation of inflammatory markers by conjugated linoleic acid isomers in human cultured astrocytes. Nutr. Neurosci. 22 (3), 207-214. doi:10.1080/ 1028415X.2017.1367130

Salas-Salvado, J., Marquez-Sandoval, F., and Bullo, M. (2006). Conjugated linoleic acid intake in humans: a systematic review focusing on its effect on body composition, glucose, and lipid metabolism. Crit. Rev. Food Sci. Nutr. 46 (6), 479-488. doi:10.1080/10408390600723953.

Salem, N., Jr., and Niebylski, C. D. (1995). The nervous system has an absolute molecular species requirement for proper function. Mol. Membr. Biol. 12 (1), 131-134. doi:10.3109/09687689509038508

Schaeffer, E. L., da Silva, E. R.A., Skaf, H. D., and Gattaz, W. F. (2010). Novaes BdeDifferential roles of phospholipases A2 in neuronal death and neurogenesis: implications for Alzheimer disease. Prog. Neuro-Psychopharmacol. Biol. Psychiatry 34 (8), 1381-1389. doi:10.1016/j.pnpbp.2010.08.019

Scheggi, S., Melis, M., De Felice, M., Aroni, S., Muntoni, A. L., Pelliccia, T., et al. (2016). PPARalpha modulation of mesolimbic dopamine transmission rescues depression-related behaviors. Neuropharmacology 110 (Pt A), 251-259. doi:10. 1016/j.neuropharm.2016.07.024

Schoonjans, K., Staels, B., and Auwerx, J. (1996). The peroxisome proliferator activated receptors (PPARS) and their effects on lipid metabolism and adipocyte differentiation. Biochim. Biophys. Acta 1302 (2), 93-109. doi:10. 1016/0005-2760(96)00066-5

Sebedio, J. L., Juaneda, P., Dobson, G., Ramilison, I., Martin, J. D., and Chardigny, J. M. (1997). Metabolites of conjugated isomers of linoleic acid (CLA) in the rat. Biochim. Biophys. Acta Lipids Lipid. Metabol. 1345 (1), 5-10. doi:10.1016/ S0005-2760(97)00015-5

Seibert, K., Masferrer, J., Zhang, Y., Gregory, S., Olson, G., Hauser, S., et al. (1995). Mediation of inflammation by cyclooxygenase-2. Agents Actions Suppl. 46, 41-50. doi:10.1007/978-3-0348-7276-8_5

Sergeeva, M. G., Aleshin, S. E., Grabeklis, S., and Reiser, G. (2010). PPAR activation has dichotomous control on the expression levels of cytosolic and secretory phospholipase A2 in astrocytes; inhibition in naive, untreated cells and enhancement in LPS-stimulated cells. J. Neurochem. 115 (2), 399-410. doi:10.1111/j.1471-4159.2010.06931.x

Shingfield, K. J., and Wallace, R. J. (2014). Synthesis of conjugated linoleic acid in ruminants and humans. RSC Catal. Ser. 19, 1. doi:10.1039/978178262021100001

Smedman, A., Basu, S., Jovinge, S., Fredrikson, G. N., and Vessby, B. (2005). Conjugated linoleic acid increased C-reactive protein in human subjects. $B r$. J. Nutr. 94 (5), 791-795. doi:10.1079/bjn20041419

Soares, J. K., de Melo, A. P., Medeiros, M. C., Queiroga, R. C., Bomfim, M. A., Santiago, E. C., et al. (2013). Anxiety behavior is reduced, and physical growth is improved in the progeny of rat dams that consumed lipids from goat milk: an elevated plus maze analysis. Neurosci. Lett. 552, 25-29. doi:10.1016/j.neulet. 2013.07.028

Stachowska, E., Dziedziejko, V., Safranow, K., Gutowska, I., Adler, G., Ciechanowicz, A., et al. (2007). Inhibition of phospholipase A(2) activity by conjugated linoleic acids in human macrophages. Eur. J. Nutr. 46 (1), 28-33. doi:10.1007/s00394-006-0626-7

Tanaka, Y., Ward, S. L., and Smith, W. L. (1987). Immunochemical and kinetic evidence for two different prostaglandin $\mathrm{H}$-prostaglandin $\mathrm{E}$ isomerases in sheep vesicular gland microsomes. J. Biol. Chem. 262 (3), 1374-1381.

Tholstrup, T., Raff, M., Straarup, E. M., Lund, P., Basu, S., and Bruun, J. M. (2008). An oil mixture with trans-10, cis-12 conjugated linoleic acid increases markers of inflammation and in vivo lipid peroxidation compared with cis-9, trans-11 conjugated linoleic acid in postmenopausal women. J. Nutr. 138 (8), 1445-1451. doi:10.1093/jn/138.8.1445

Trinchese, G., Cavaliere, G., Cimmino, F., Catapano, A., Carta, G., Pirozzi, C., et al. (2020). Decreased metabolic flexibility in skeletal muscle of rat fed with a highfat diet is recovered by individual CLA isomer supplementation via converging protective mechanisms. Cells 9 (4), 823. doi:10.3390/cells9040823

Trinchese, G., Cavaliere, G., De Filippo, C., Aceto, S., Prisco, M., Chun, J. T., et al. (2018). Human milk and donkey milk, compared to cow milk, reduce inflammatory mediators and modulate glucose and lipid metabolism, acting on mitochondrial function and oleylethanolamide levels in rat skeletal muscle. Front. Physiol. 9, 32. doi:10.3389/fphys.2018.00032

Tufano, M., and Pinna, G. (2020). Is there a future for PPARs in the treatment of neuropsychiatric disorders?. Molecules 25 (5), 1062. doi:10.3390/ molecules 25051062

Ujihara, M., Tsuchida, S., Satoh, K., Sato, K., and Urade, Y. (1988). Biochemical and immunological demonstration of prostaglandin D2, E2, and F2 alpha formation from prostaglandin $\mathrm{H} 2$ by various rat glutathione S-transferase isozymes. Arch. Biochem. Biophys. 264 (2), 428-437. doi:10.1016/0003-9861(88)90308-6

Unsworth, A. J., Flora, G. D., and Gibbins, J. M. (2018). Non-genomic effects of nuclear receptors: insights from the anucleate platelet. Cardiovasc. Res. 114 (5), 645-655. doi:10.1093/cvr/cvy044

Van der Ouderaa, F. J., Buytenhek, M., Nugteren, D. H., and Van Dorp, D. A. (1977). Purification and characterisation of prostaglandin endoperoxide synthetase from sheep vesicular glands. Biochim. Biophys. Acta 487 (2), 315-331. doi:10.1016/0005-2760(77)90008-x

Wahli, W., and Michalik, L. (2012). PPARs at the crossroads of lipid signaling and inflammation. Trends Endocrinol. Metabol. 23 (7), 351-363. doi:10.1016/j.tem. 2012.05.001

Wanders, A. J., Brouwer, I. A., Siebelink, E., and Katan, M. B. (2010a). Effect of a high intake of conjugated linoleic acid on lipoprotein levels in healthy human subjects. PloS One 5 (2), e9000. doi:10.1371/journal.pone.0009000

Wanders, A. J., Leder, L., Banga, J. D., Katan, M. B., and Brouwer, I. A. (2010b). A high intake of conjugated linoleic acid does not affect liver and kidney function tests in healthy human subjects. Food Chem. Toxicol. 48 (2), 587-590. doi:10. 1016/j.fct.2009.11.036

Wang, H., Liu, T., Wang, J., Qi, Y., Ge, D., and Guan, S. (2011). Isomer-specific effects of conjugated linoleic acid on proliferative activity of cultured neural progenitor cells. Mol. Cell. Biochem. 358 (1, 2), 13-20. doi:10.1007/s11010-0110914-2

Wang, Y. W., and Jones, P. J. (2004). Conjugated linoleic acid and obesity control: efficacy and mechanisms. Int. J. Obes. Relat. Metab. Disord. 28 (8), 941-955. doi:10.1038/sj.ijo.0802641

Warden, A., Truitt, J., Merriman, M., Ponomareva, O., Jameson, K., Ferguson, L. B., et al. (2016). Localization of PPAR isotypes in the adult mouse and human brain. Sci. Rep. 6, 27618. doi:10.1038/srep27618 
Whigham, L. D., Cook, E. B., Stahl, J. L., Saban, R., Bjorling, D. E., Pariza, M. W., et al. (2001). CLA reduces antigen-induced histamine and PGE(2) release from sensitized Guinea pig tracheae. Am. J. Physiol. Regul. Integr. Comp. Physiol. 280 (3), R908-R912. doi:10.1152/ajpregu.2001.280.3.R908

Whigham, L. D., Higbee, A., Bjorling, D. E., Park, Y., Pariza, M. W., and Cook, M. E. (2002). Decreased antigen-induced eicosanoid release in conjugated linoleic acid-fed Guinea pigs. Am. J. Physiol. Regul. Integr. Comp. Physiol. 282 (4), R1104-R1112. doi:10.1152/ajpregu.00075.2001

Wightman, P. D., and Dallob, A. (1990). Regulation of phosphatidylinositol breakdown and leukotriene synthesis by endogenous prostaglandins in resident mouse peritoneal macrophages. J. Biol. Chem. 265 (16), 9176-9180.

$\mathrm{Xu}$, J., and Drew, P. D. (2007). Peroxisome proliferator-activated receptorgamma agonists suppress the production of IL-12 family cytokines by activated glia. J. Immunol. 178 (3), 1904-1913. doi:10.4049/jimmunol.178. 3.1904

Yasojima, K., Schwab, C., McGeer, E. G., and McGeer, P. L. (1999). Distribution of cyclooxygenase- 1 and cyclooxygenase- 2 mRNAs and proteins in human brain and peripheral organs. Brain Res. 830 (2), 226-236. doi:10.1016/s0006-8993(99) 01389-x

Zamberletti, E., Piscitelli, F., De Castro, V., Murru, E., Gabaglio, M., Colucci, P., et al. (2017). Lifelong imbalanced LA/ALA intake impairs emotional and cognitive behavior via changes in brain endocannabinoid system. J. Lipid Res. 58 (2), 301-316. doi:10.1194/jlr.M068387

Conflict of Interest: The authors declare that the research was conducted in the absence of any commercial or financial relationships that could be construed as a potential conflict of interest.

Copyright (c) 2021 Murru, Carta, Manca, Sogos, Pistis, Melis and Banni. This is an open-access article distributed under the terms of the Creative Commons Attribution License (CC BY). The use, distribution or reproduction in other forums is permitted, provided the original author(s) and the copyright owner(s) are credited and that the original publication in this journal is cited, in accordance with accepted academic practice. No use, distribution or reproduction is permitted which does not comply with these terms. 